\begin{tabular}{|} 
Ambiente \& Água - An Interdisciplinary Journal of Applied Science \\
ISSN 1980-993X - doi:10.4136/1980-993X \\
www.ambi-agua.net \\
E-mail: ambi.agua@gmail.com
\end{tabular}

\title{
Efeito da aplicação de diferentes lâminas de irrigação e doses de nitrogênio e potássio na produção do capim Tanzânia
}

\author{
doi: 10.4136/ambi-agua.1595
}

Received: 21 Jan. 2015; Accepted: 07 Mar. 2015

\author{
Ednaldo Miranda de Oliveira ${ }^{1^{*}}$; Jair da Costa Oliveira Filho ${ }^{2}$; \\ Rubens Alves de Oliveira ${ }^{3}$; Reginaldo Miranda de Oliveira ${ }^{3}$; \\ Paulo Roberto Cecon ${ }^{3}$; Antônio Carlos Cóser ${ }^{4}$ \\ ${ }^{1}$ Instituto Federal do Espírito Santo (IFES), Santa Teresa, ES, Brasil \\ ${ }^{2}$ Universidade Federal do Tocantins (UFT), Gurupi, TO, Brasil \\ ${ }^{3}$ Universidade Federal de Viçosa (UFV), Viçosa, MG, Brasil \\ ${ }^{4}$ Empresa Brasileira de Pesquisa Agropecuária (EMBRAPA), Juiz de Fora, MG, Brasil \\ *Autor correspondente: e-mail: ednaldo.oliveira@ifes.edu.br, \\ jair@uft.edu.br, rubens@ufv.br, reginaldomoliveira@hotmail.com, \\ cecon@ufv.br, acoser1@yahoo.com.br
}

\section{RESUMO}

O estudo da interação entre nitrogênio, potássio e quantidade de água são importantes na definição das doses ideais desses fatores, a fim de otimizar a produção das forragem. Assim, teve-se como objetivo neste trabalho avaliar os efeitos da aplicação de diferentes lâminas de água e doses de nitrogênio e potássio, na produção do capim Tanzânia, no sul do Estado do Tocantins. Para estudar a influência das lâminas de água e das combinações das doses de $\mathrm{N}$ e $\mathrm{K}_{2} \mathrm{O}$ no capim, nos períodos seco e chuvoso do ano, determinou-se ao longo do experimento a produção de forragem. A máxima produtividade no mesmo período foi de $8.706 \mathrm{~kg} \mathrm{ha}^{-1}$, com a dose de $576,79 \mathrm{~kg} \mathrm{ha}^{-1}$ de $\mathrm{N}: 0,8 \mathrm{~K}_{2} \mathrm{O}$ e lâmina de água de $116 \% \mathrm{ET}_{\mathrm{c}}$, resultando em aumento de $246 \%$. No período chuvoso, a menor produtividade foi de $6.815 \mathrm{~kg} \mathrm{ha}^{-1}$, com dose de $100 \mathrm{~kg} \mathrm{ha}^{-1}$ ano $^{-1}$ de $\mathrm{N}: 0,8 \mathrm{~K}_{2} \mathrm{O}$, na ausência da irrigação. A maior produtividade no mesmo período foi de $11.710 \mathrm{~kg} \mathrm{ha}^{-1}$, com a dose estimada de $672,9 \mathrm{~kg} \mathrm{ha}^{-1}$ ano $^{-1}$ de $\mathrm{N}: 0,8$ $\mathrm{K}_{2} \mathrm{O}$ e lâmina de água aplicada de $120 \%$ da $\mathrm{ET}_{\mathrm{c}}$, resultando em um aumento de $71,8 \%$. Concluiu-se então nesse trabalho que a produtividade máxima de matéria seca estimada com as equações ajustadas foi de $20.216 \mathrm{~kg} \mathrm{ha}^{-1}$ ano $^{-1}$ obtida com lâmina de água aplicada igual a $949 \mathrm{~mm}$ e com a aplicação de $630 \mathrm{~kg} \mathrm{ha}^{-1} \mathrm{ano}^{-1}$ da mistura de nitrogênio e potássio na proporção de uma unidade de nitrogênio para 0,8 unidades de potássio.

Palavras-chave: adubação nitrogenada, irrigação de pastagem, produtividade de forragem.

\section{Effect of different dephts water and doses of nitrogen and potassium in production of Tanzania grass}

\begin{abstract}
The study of the interaction between nitrogen, potassium and water content are important in defining the optimum doses of these factors in order to optimize the production of fodder. Thus, it had as objective in this study was to evaluate the effects of applying different water
\end{abstract}


depths and nitrogen and potassium, in the production of Tanzania grass in southern state of Tocantins. To study the influence of water levels and combinations of $\mathrm{N}$ and $\mathrm{K}_{2} \mathrm{O}$ in the grass, the dry and wet periods of the year, it was determined during the experiment forage production. The highest yield in the same period was $8706 \mathrm{~kg} \mathrm{ha}^{-1}$, with the dose of $576.79 \mathrm{~kg}$ $\mathrm{ha}^{-1} \mathrm{~N}$ : $0.8 \mathrm{~K}_{2} \mathrm{O}$ and water depth of $116 \% \mathrm{ETc}$, resulting in an increase of $246 \%$. During the rainy season, the lowest yield was $6815 \mathrm{~kg} \mathrm{ha}^{-1}$, a dose of $100 \mathrm{~kg} \mathrm{ha}^{-1} \mathrm{yr}^{-1} \mathrm{~N}$ : $0.8 \mathrm{~K}_{2} \mathrm{O}$ in the absence of irrigation. The highest yield in the same period was $11,710 \mathrm{~kg} \mathrm{ha}^{-1}$, with the estimated dose of $672.9 \mathrm{~kg} \mathrm{ha}^{-}{ }^{1} \mathrm{yr}^{-1} \mathrm{~N}: 0.8 \mathrm{~K}_{2} \mathrm{O}$ and applied water depth of $120 \%$ of ETc, resulting in a increase of $71.8 \%$. It was therefore concluded that work that the maximum dry matter yield estimated to the adjusted model was $20,216 \mathrm{~kg} \mathrm{ha}^{-1} \mathrm{yr}^{-1}$ obtained with the applied water depth equal to $949 \mathrm{~mm}$ and with the application of $630 \mathrm{~kg} \mathrm{ha}^{-1}$ year $^{-1}$ of nitrogen and potassium mixture in the ratio of a nitrogen unit for 0.8 potassium units.

Keywords: forage yield, nitrogen fertilization, pasture irrigation.

\section{INTRODUÇÃO}

Dentre diversos desafios enfrentados pela pecuária brasileira um que merece atenção é a manutenção da oferta de pastagem em quantidade e qualidade o ano todo. Fatores como as condições climáticas e a disponibilidade de nutrientes no solo para o bom desenvolvimento das plantas são cruciais para a produção de forragem (Roma et al., 2012).

A utilização de insumos, como irrigação e fertilizantes, dependerá do clima e da relação custo/benefício. Os custos dificilmente poderão ser alterados para determinado nível de utilização de insumos; por isso, os esforços devem concentrar-se na maximização dos benefícios, ou seja, na otimização da produção. Dessa forma, há necessidade de aumentar a produtividade, o que pode ser alcançado com o incremento da capacidade de suporte das pastagens e com a melhoria do ganho de peso dos animais (Alencar et al., 2009).

A sazonalidade da produção de forragem é outro fator importante a ser considerado na pecuária intensiva. No Brasil Central, no período de seca, ocorre decréscimo de até $10 \%$ na produção de forragem, considerando o total anual (Alencar et al., 2010).

O manejo da fertilidade do solo, a prática da adubação, o conhecimento das exigências nutricionais, os efeitos da irrigação e do clima são fatores de grande importância para a prática do manejo de pastagens, que se reflete na maior ou menor produção de forragem (Dias Filho, 2011).

Diante da diversidade de solo e clima no Brasil, viu-se a necessidade então de estudar a interação entre nitrogênio, potássio e quantidade de água, definindo-se as doses ideais desses fatores, a fim de otimizar a produção de forragem. Nesse contexto, teve-se como objetivo neste trabalho avaliar os efeitos da aplicação de diferentes lâminas de água e doses de nitrogênio e potássio, na produção do capim Tanzânia, no sul do Estado do Tocantins, buscando-se encontrar níveis ótimos desses fatores que otimizem a produção de forragem dessa gramínea.

\section{MATERIAL E MÉTODOS}

$\mathrm{O}$ experimento foi conduzido com a variedade Panicum maximum cv. Tanzânia na Estação Experimental do Campus Universitário de Gurupi, Fundação Universidade do Tocantins, Município de Gurupi, TO, (11 $45^{\circ} \mathrm{S}, 49^{\circ} 03^{\prime} \mathrm{W}$, altitude $\left.287 \mathrm{~m}\right)$.

Antes da implantação do experimento foram coletadas amostras compostas de solo, na camada de $30 \mathrm{~cm}$ de profundidade. No Laboratório de Análise de Solos do Departamento de Solos da Universidade Federal de Viçosa foram realizadas análises química e física do solo para a determinação da densidade, ponto de murcha e capacidade de campo, obtendo-se os 
valores de $1,51 \mathrm{~g} \mathrm{~cm}^{-3}, 0,089 \mathrm{~g} \mathrm{~g}^{-1}$ e $0,145 \mathrm{~g} \mathrm{~g}^{-1}$, respectivamente. A densidade do solo, foi determinada pelo método do anel volumétrico, descrita por Bernardo et al. (2006). O ponto de murcha permanente foi determinado utilizando-se o método do Extrator de Richards e a capacidade de campo foi determinada pelo método de campo (Bernardo et al., 2006).

$\mathrm{Na}$ área experimental foi instalado um sistema de irrigação por aspersão em linha (Line Source Sprinkler System), de acordo com metodologia descrita por Hanks et al. (1976) e citada por Silva et al. (2014). Esse sistema, desenvolvido para fins experimentais, consiste na instalação de uma linha lateral na posição central da área experimental, com os aspersores bem próximos, de modo a se obter grande sobreposição dos jatos de água. Esse arranjo permite a aplicação de lâminas de irrigação decrescente ao se afastar dos aspersores instalados na parte central da área de cultivo com a pastagem, ou seja, as plantas próximas aos aspersores recebem mais áugua enquanto as mais afastadas recebem menos água.

$\mathrm{O}$ experimento foi conduzido em esquema de faixas ao longo da linha de aspersores, utilizando-se o delineamento inteiramente casualizado com quatro repetições.

As parcelas consistiram de quatro combinações de doses de $\mathrm{N}$ e $\mathrm{K}_{2} \mathrm{O}(\mathrm{D} 1=100+80$, $\left.\mathrm{D} 2=300+240, \mathrm{D} 3=500+400, \mathrm{D} 4=700+560 \mathrm{~kg} \mathrm{ha}^{-1}\right)$, de forma que as combinações de $\mathrm{N}$ e $\mathrm{K}_{2} \mathrm{O}$ guardam uma relação de $1 \mathrm{~N}: 0,8 \mathrm{~K}_{2} \mathrm{O}$. A fonte de nitrogênio foi a uréia e a de potássio, o cloreto de potássio.

As parcelas experimentais possuíam $6 \mathrm{~m}$ de largura e $18 \mathrm{~m}$ de comprimento, as quais foram subdivididas em seis partes iguais, com $6 \times 3 \mathrm{~m}\left(18 \mathrm{~m}^{2}\right)$, com bordadura de $0,5 \mathrm{~m}$ de cada lado, resultando em subparcelas com $5 \times 2 \mathrm{~m}$, área útil de $10 \mathrm{~m}^{2}$, dispostas em faixas que representam as lâminas de água aplicadas proporcionais à evapotranspiração da cultura $(\mathrm{L} 0=0, \mathrm{~L} 1=18 \% \mathrm{ETc}, \mathrm{L} 2=45 \% \mathrm{ETc}, \mathrm{L} 3=77 \% \mathrm{ETc}, \mathrm{L} 4=100 \% \mathrm{ETc}$ e L5 $=120 \% \mathrm{ETc})$. Cada subparcela foi subdividida no tempo, em dois períodos do ano, para serem realizadas as análises qualitativas da forragem ao longo do ano. O primeiro período, que apresentava menores precipitações médias, compreendia os meses entre maio e outubro, foi chamado de período seco. O segundo, que apresentava maiores precipitações médias, compreendia os meses entre novembro e abril, foi chamado de período chuvoso.

As coletas sistemáticas das amostras do capim e os pastejos monitorados nas subparcelas, foram realizadas de maneira que o resíduo pós-pastejo apresentasse 15 a $20 \%$ de folhas verdes remanescentes, conforme recomendação da Embrapa Gado de Leite (Deresz, 1994).

O monitoramento da umidade do solo foi efetuado com tensiômetros de punção com leitura digital, instalados a $15 \mathrm{~cm}$ de profundidade nos tratamentos D3L4, (subparcela com $100 \%$ da reposição da evapotranspiração das parcelas com doses de $500 \mathrm{~kg}$ de N com $400 \mathrm{~kg}$ de $\mathrm{K}_{2} \mathrm{O}$ ).

As leituras tensiométricas foram feitas pela manhã, às 9 horas. Quando o valor médio das tensões dos quatro tensiômetros instalados a $15 \mathrm{~cm}$ de profundidade era igual ou superior a 40 $\mathrm{kPa}$, fazia-se a irrigação.

O tempo de irrigação para elevar a umidade do solo à capacidade de campo, nas parcelas com reposição integral da $\mathrm{ET}_{\mathrm{c}}(\mathrm{L} 4)$, foi calculado com base na lâmina total necessária (Equação 1) e na intensidade líquida média de aplicação de água dos aspersores.

$$
\mathrm{L}=\frac{(\mathrm{CC}-\mathrm{UA})}{10} \mathrm{D} \mathrm{Z} \frac{1}{\mathrm{Ea}}
$$

em que:

L: é lâmina total necessária (mm);

CC: é capacidade de campo (\% peso);

UA: é umidade do solo na tensão de aproximadamente $40 \mathrm{kPa}$ (\% peso); 
D: é densidade do solo $\left(\mathrm{g} \mathrm{cm}^{-3}\right)$;

Z: é profundidade efetiva do sistema radicular $(\mathrm{cm}) ; \mathrm{e}$

Ea: é eficiência de aplicação de água (decimal).

Simultaneamente ao acompanhamento da umidade do solo via tensiometria, foram coletados dados meteorológicos com uso de uma estação meteorológica automática.

$\mathrm{O}$ experimento foi conduzido seguindo-se um esquema de parcelas sub-subdivididas, tendo-se nas parcelas quatro combinações de doses de $\mathrm{N}$ e $\mathrm{K}_{2} \mathrm{O}$ e, nas subparcelas, as lâminas de água e nas subsubparcelas os dois períodos do ano: período seco e período chuvoso.

Os dados foram submetidos às análises de variância e de regressão. Para o fator qualitativo, as médias foram comparadas pelo teste de Tukey a 5\% de probabilidade. Para os fatores quantitativos, os modelos foram escolhidos com base na significância dos coeficientes de regressão, utilizando-se o teste $t$ a $5 \%$ de probabilidade. Para análises estatísticas foi utilizado o programa "SAEG 9.1", desenvolvido na UFV.

Para estudar a influência das lâminas de água e das combinações das doses de $\mathrm{N}_{\text {e }} \mathrm{K}_{2} \mathrm{O}$ no capim Tanzânia, nos dois períodos do ano, determinou-se ao longo do experimento a produção de forragem (massa seca).

Toda a massa verde colhida foi acondicionada em sacos plásticos, devidamente identificados. As amostras foram levadas à estufa a $105^{\circ} \mathrm{C}$, por 24 horas para determinação da matéria seca. A pesagem foi realizada uma hora após a retirada do material da estufa (Sanches et al., 2015).

\section{RESULTADOS E DISCUSSÃO}

Durante o período seco do ano, a produção de matéria seca (MS) do capim Tanzânia variou de forma quadrática com as doses de $\mathrm{N}$ : $0,8 \mathrm{~K}_{2} \mathrm{O}(\mathrm{p}<0,01)$ e lâminas aplicadas $(\mathrm{p}<0,01)$, de acordo com a Equação 2 e a Figura 1a. Enquanto no período chuvoso, variou de forma quadrática com as doses do adubo combinado $\mathrm{N}$ : $0,8 \mathrm{~K}_{2} \mathrm{O}(\mathrm{p}<0,01)$ e linear com as lâminas de água aplicadas ( $<<0,10)$, Equação 3 e Figura $1 b$.

A menor produtividade no período seco foi de $2.523 \mathrm{~kg} \mathrm{ha}^{-1}$ de MS, com dose de $100 \mathrm{~kg} \mathrm{ha}^{-1}$ ano $^{-1}$ de $\mathrm{N}: 0,8 \mathrm{~K}_{2} \mathrm{O}$, na ausência da irrigação $\left(0 \% \mathrm{ET}_{\mathrm{c}}\right)$. A máxima produtividade no mesmo período foi de $8.706 \mathrm{~kg} \mathrm{ha}^{-1}$ de MS, com a dose de $576,79 \mathrm{~kg} \mathrm{ha}^{-1}$ de $\mathrm{N}: 0,8 \mathrm{~K}_{2} \mathrm{O}$ e lâmina de água de $116 \% \mathrm{ET}_{\mathrm{c}}$, resultando em aumento de $246 \%$. O incremento de produtividade demonstrado pela equação 03 e da Figura 1(a) evidencia a importância da irrigação e da adubação nitrogenada e potássica no aumento do potencial produtivo do capim Tanzânia no período seco do ano.

A partir da Equação 2 para a estimativa da produtividade de matéria seca no período seco, mantendo as lâminas de água constantes e variando as doses do adubo, obteve-se a Figura 2a. Nessa figura, pode-se observar que as lâminas 100 e $120 \%$ da ET $_{c}$ tiveram respostas semelhantes e que a irrigação foi mais eficiente no período seco para ganhos de produtividade do capim Tanzânia. A dose de máxima produtividade foi de $577 \mathrm{~kg} \mathrm{ha}^{-1}$ ano $^{-1}$ de $\mathrm{N}$ : $0,8 \mathrm{~K}_{2} \mathrm{O}$. No entanto, quando fixaram as doses de adubo e variou a lâmina (Figura 3a), observou-se aumento de produtividade de matéria seca até a dose de $500 \mathrm{~kg} \mathrm{ha}^{-1}$ ano ${ }^{-1}$ de $\mathrm{N}$ : $0,8 \mathrm{~K}_{2} \mathrm{O}$, obtendo-se um valor inferior com a aplicação da dose de $700 \mathrm{~kg} \mathrm{ha}^{-1} \mathrm{ano}^{-1} \mathrm{de}$ $\mathrm{N}: 0,8 \mathrm{~K}_{2} \mathrm{O}$.

$$
\begin{array}{ll}
\mathrm{MS}=1.441,47+11,84 \mathrm{D}-0,01 \mathrm{D}^{2}+66,22 \mathrm{~L}-0,28^{* *} \mathrm{~L}^{2} & \mathrm{R}^{2}=0,80 \\
\hat{\mathrm{MS}}=5.227,58+17,1504^{* *} \mathrm{D}-0,0127353^{* *} \mathrm{D}^{2}+5,9053^{\mathrm{ns}} \mathrm{L} & \mathrm{R}^{2}=0,81
\end{array}
$$




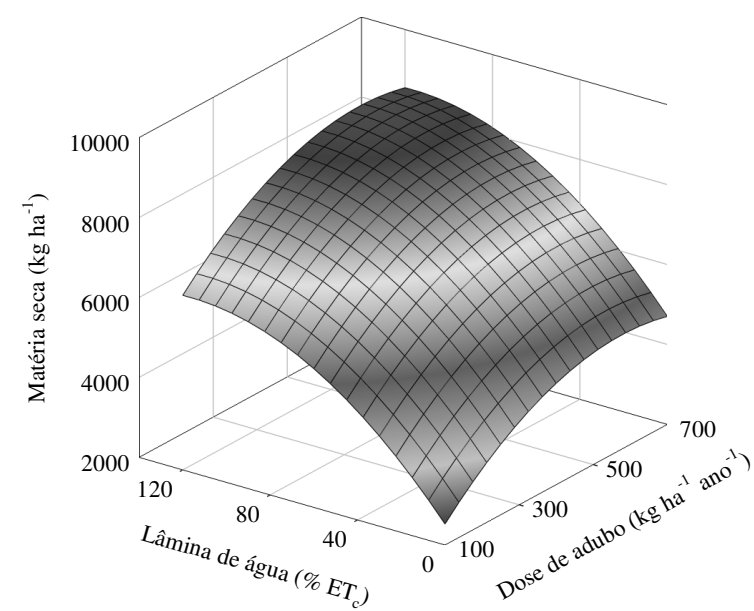

(a)

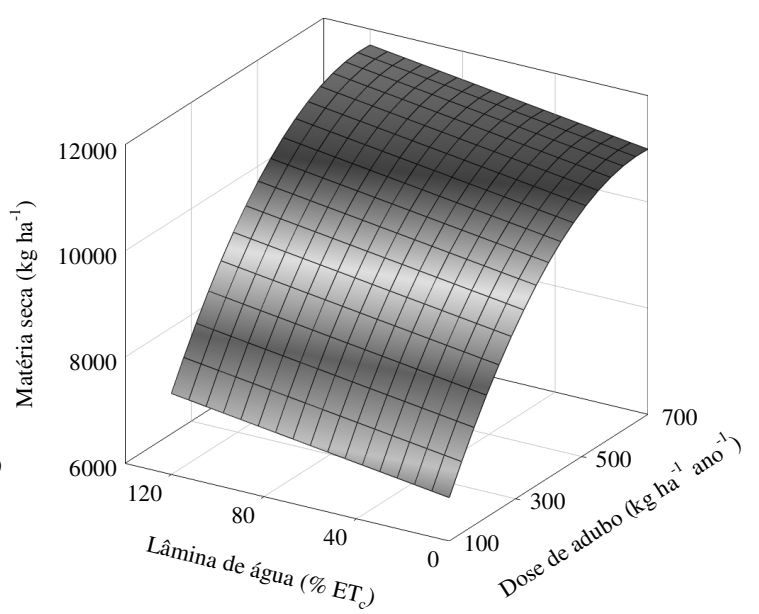

(b)

Figura 1. Estimativa da produtividade de matéria seca do capim Tanzânia, em função da dose de nitrogênio e potássio e da lâmina de água aplicada, durante os períodos seco (a) e chuvoso (b).

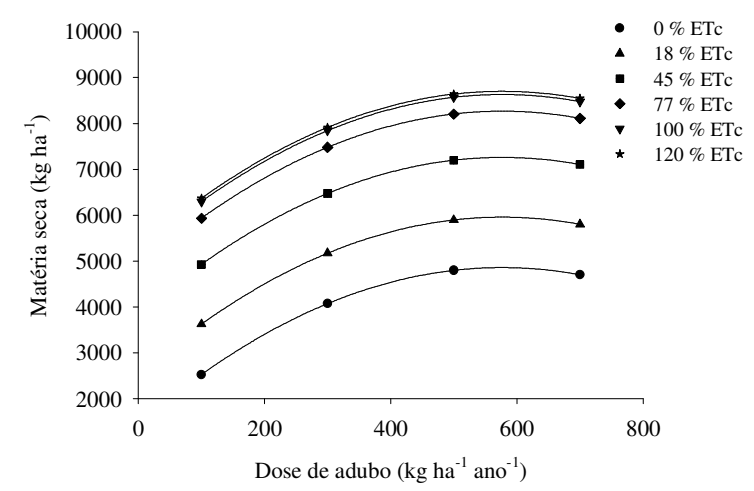

(a)

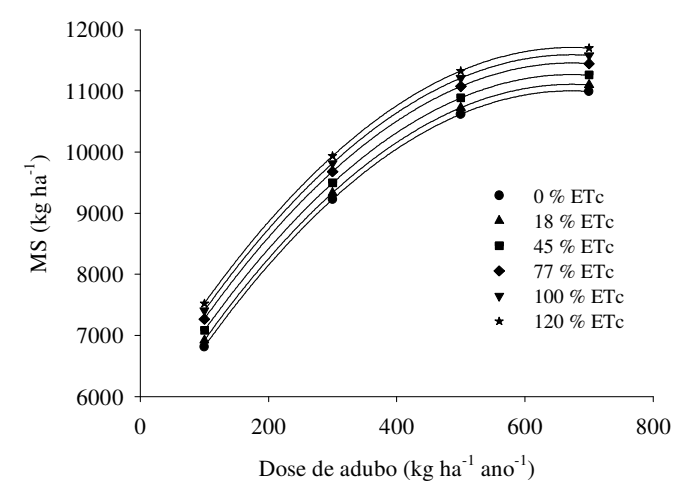

(b)

Figura 2. Produtividade de matéria seca do capim Tanzânia nas diferentes lâminas aplicadas $\left(\% \mathrm{ET}_{\mathrm{c}}\right)$, em função da dose do adubo $\left(\mathrm{kg} \mathrm{ha}^{-1}\right.$ de $\left.\mathrm{N}: 0,8 \mathrm{~K}_{2} \mathrm{O}\right)$, durante os períodos seco (a) e chuvoso (b).

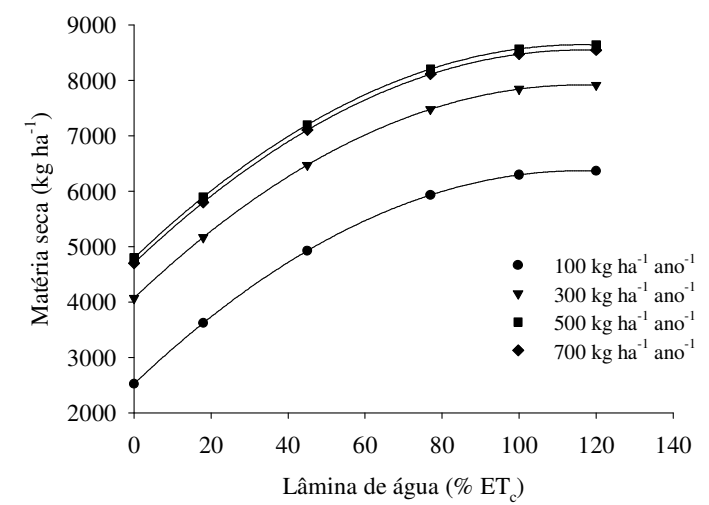

(a)

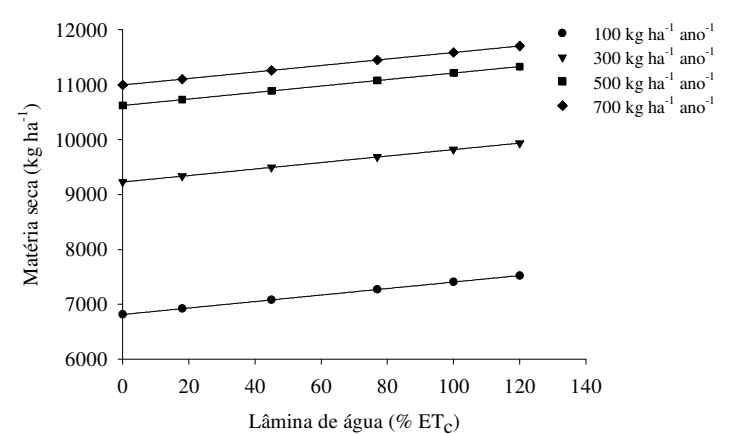

(b)

Figura 3. Produtividade de matéria seca do capim Tanzânia nas diferentes doses do adubo $\left(\mathrm{kg} \mathrm{ha}^{-1}\right.$ de $\left.\mathrm{N}: 0,8 \mathrm{~K}_{2} \mathrm{O}\right)$, em função das lâminas aplicadas $\left(\% \mathrm{ET}_{\mathrm{c}}\right)$, durante os períodos seco (a) e chuvoso (b). 
A menor produtividade no período chuvoso foi de $6.815 \mathrm{~kg} \mathrm{ha}^{-1}$ de MS, com dose de 100 $\mathrm{kg} \mathrm{ha}^{-1} \mathrm{ano}^{-1}$ de $\mathrm{N}: 0,8 \mathrm{~K}_{2} \mathrm{O}$, na ausência da irrigação $\left(0 \% \mathrm{ET}_{\mathrm{c}}\right)$. A maior produtividade no mesmo período foi de $11,710 \mathrm{~kg} \mathrm{ha}^{-1}$ de MS, com a dose estimada de $672,9 \mathrm{~kg} \mathrm{ha}^{-1}$ ano $^{-1} \mathrm{de}$ $\mathrm{N}$ : $0,8 \mathrm{~K}_{2} \mathrm{O}$ e lâmina de água aplicada de $120 \%$ da $\mathrm{ET}_{\mathrm{c}}$, resultando em um aumento de $71,8 \%$.

Como no período seco a produtividade máxima de MS foi igual a $8.706 \mathrm{~kg} \mathrm{ha}^{-1}$, esse valor representa $74 \%$ da produtividade máxima obtida no período chuvoso.

A Figura 2 b foi obtida a partir da Equação 3 para estimativa de produtividade de matéria seca no período chuvoso, mantendo-se as lâminas constantes e variando-se as doses de adubo. Comparando as Figuras $2 \mathrm{a}$ e $2 \mathrm{~b}$, observou-se que o efeito das doses do adubo na produtividade de matéria seca no capim Tanzânia foi mais pronunciado no período chuvoso, devido à elevação da temperatura e ao aumento do fotoperíodo. Entretanto, como era esperado, o efeito da lâmina de água aplicado na irrigação foi maior no período seco do ano.

A Figura $3 \mathrm{~b}$ foi também obtida a partir da Equação 3, porém, mantendo-se as doses do adubo constantes e variando-se as lâminas. Nessa figura, observa-se comportamento linear e crescente do ganho de produtividade em função da lâmina aplicada e que o aumento das doses resultou em ganhos em menores proporções na produtividade de matéria seca do capim Tanzânia. Comparando as Figuras 3a e 3b, observa-se comportamento quadrático da lâmina de água aplicada na produtividade de matéria seca do capim Tanzânia no período seco e linear no período chuvoso e que lâminas acima de $116 \% \mathrm{ET}_{\mathrm{c}}$ provocam queda na produtividade.

$\mathrm{Na}$ Tabela 1 são apresentadas as produtividades de matéria seca do capim Tanzânia para a combinação de período, dose de adubo e lâmina de água. Na dose de $100 \mathrm{~kg} \mathrm{ha}^{-1} \mathrm{ano}^{-1} \mathrm{de} \mathrm{N}$ : $0,8 \mathrm{~K}_{2} \mathrm{O}$, as produtividades de matéria seca no período seco diferiram das obtidas no período chuvoso para as lâminas de 0,18 e $45 \%$ da $\mathrm{ET}_{\mathrm{c}}$. Nas demais doses, a produtividade de matéria seca no período seco não diferiu daquela do período chuvoso somente na lâmina de $45 \%$ da $\mathrm{ET}_{\mathrm{c}}$ e na dose de $300 \mathrm{~kg} \mathrm{ha}^{-1} \mathrm{ano}^{-1}$, na lâmina de $120 \%$ da $\mathrm{ET}_{\mathrm{c}}$ com a dose de $500 \mathrm{~kg} \mathrm{ha}^{-1} \mathrm{ano}^{-1}$ e na lâmina de $100 \%$ da $\mathrm{ET}_{\mathrm{c}}$ com a dose de $700 \mathrm{~kg} \mathrm{ha}^{-1} \mathrm{ano}^{-1}$.

Tabela 1. Valores médios da produtividade de matéria seca $\left(\mathrm{kg} \mathrm{ha}^{-1}\right)$ do capim Tanzânia das combinações de período, lâmina de água e dose de adubo.

\begin{tabular}{|c|c|c|c|c|}
\hline \multirow{3}{*}{$\begin{array}{l}\text { Lâmina de Água } \\
\qquad\left(\% \mathrm{ET}_{\mathrm{c}}\right)\end{array}$} & \multicolumn{4}{|c|}{ Dose de $\mathrm{N}: 0,8 \mathrm{~K}_{2} \mathrm{O}\left(\mathrm{kg} \mathrm{ha}^{-1} \mathrm{ano}^{-1}\right)$} \\
\hline & \multicolumn{2}{|c|}{100} & \multicolumn{2}{|c|}{300} \\
\hline & P1 & P2 & P1 & $\mathrm{P} 2$ \\
\hline 0 & $3.614 \mathrm{~b}$ & $7.351 \mathrm{a}$ & $3.696 \mathrm{~b}$ & $9.069 \mathrm{a}$ \\
\hline 18 & $4.706 \mathrm{~b}$ & $7.397 \mathrm{a}$ & $5,113 \mathrm{~b}$ & $1.360 \mathrm{a}$ \\
\hline 45 & $4.807 \mathrm{~b}$ & $6.491 \mathrm{a}$ & $6.097 \mathrm{a}$ & $9.953 \mathrm{a}$ \\
\hline 77 & $6.010 \mathrm{a}$ & $7.068 \mathrm{a}$ & $7.344 \mathrm{~b}$ & $9.344 \mathrm{a}$ \\
\hline 100 & $5.570 \mathrm{a}$ & $7.418 \mathrm{a}$ & $7.618 \mathrm{~b}$ & $10.751 \mathrm{a}$ \\
\hline \multirow[t]{3}{*}{120} & $6.562 \mathrm{a}$ & $5.117 \mathrm{a}$ & $8.626 \mathrm{~b}$ & $11.241 \mathrm{a}$ \\
\hline & \multicolumn{2}{|c|}{500} & \multicolumn{2}{|c|}{700} \\
\hline & P1 & $\mathrm{P} 2$ & P1 & $\mathrm{P} 2$ \\
\hline 0 & $4.945 \mathrm{~b}$ & $9.953 \mathrm{a}$ & $4.150 \mathrm{~b}$ & $10.774 \mathrm{a}$ \\
\hline 18 & $5.064 \mathrm{~b}$ & $9.834 \mathrm{a}$ & $5.247 \mathrm{~b}$ & $11.263 \mathrm{a}$ \\
\hline 45 & $7.334 \mathrm{~b}$ & $10.664 \mathrm{a}$ & $7.269 \mathrm{~b}$ & $12.074 \mathrm{a}$ \\
\hline 77 & $8.704 \mathrm{~b}$ & $11.048 \mathrm{a}$ & $8.041 \mathrm{~b}$ & $13.284 \mathrm{a}$ \\
\hline 100 & $8.818 \mathrm{~b}$ & $11.496 \mathrm{a}$ & $9.229 \mathrm{a}$ & $10.287 \mathrm{a}$ \\
\hline 120 & $8.938 \mathrm{a}$ & $10.651 \mathrm{a}$ & $8.640 \mathrm{~b}$ & $11.130 \mathrm{a}$ \\
\hline
\end{tabular}

*Médias seguidas de pelo menos uma mesma letra nas linhas para cada lâmina de água e dose de adubo não diferem entre si, a 5\% de probabilidade, pelo teste de Tukey. $\mathrm{P} 1$ = período seco e P2 = período chuvoso. 
A maior produtividade de MS do capim Tanzânia foi de $20.215 \mathrm{~kg} \mathrm{ha}^{-1} \mathrm{ano}^{-1}$. Na literatura, o potencial produtivo (Jank et al., 2005) dessa cultivar é de $26 \mathrm{t} \mathrm{ha}^{-1}$ ano $^{-1}$. Segundo Pinheiro et al. (2002), o potencial produtivo simulado para a região sul do Estado do Tocantins é de $37.125 \mathrm{~kg} \mathrm{ha}^{-1} \mathrm{ano}^{-1}$. Esse valor inferior de produtividade alcançada neste experimento pode ser justificado pela diferença metodológica da estimativa da produção de matéria seca, em que nesse caso foi computado apenas o material passível de ser consumido pelo animal, o que pode ser constatado pelos resultados obtidos por Alencar et al. (2009), onde foi adotado metodologia semelhante de simulação de pastejo em capim Tanzânia, em que a produtividade média de dois anos foi de $66 \%$ da observada neste trabalho.

Soares Filho et al. (2002), cultivando capim Tanzânia em sistema não-irrigado, no Município de Piacatu, SP, com adubação nitrogenada de $200 \mathrm{~kg} \mathrm{ha}^{-1}$ ano $^{-1}$ nas estações seca e chuvosa, obteve produtividade média de MS na estação seca equivalente a $18 \%$ da obtida na estação chuvosa. Neste trabalho, a relação foi de $74,3 \%$. Neste trabalho, a relação foi de $74,3 \%$, levando-nos a inferir que a irrigação e adubações nitrogenada e potássica ajudam a equilibrar a produção de forragem entre o período seco e o chuvoso na região sul do Estado de Tocantins.

Observa-se, na Tabela 1, que a produtividade de MS nos diversos tratamentos foi, em geral, maior $(\mathrm{p}<0,05)$ no período chuvoso em relação ao período seco. Tal resultado pode ser decorrente das menores temperaturas e, ou, das maiores amplitudes térmicas observadas no período seco. Dessa forma, pode ter havido alteração no metabolismo da planta, resultando em menor produção de MS.

Assim, o uso da irrigação torna-se mais um atrativo como forma de seguro dos investimentos na produção de forragem, no caso de ocorrência de veranicos, além de melhorar a eficiência de uso de adubos nitrogenados e potássicos.

Na Figura 4 são apresentadas as produções de matéria seca do capim Tanzânia e a variação da temperatura mínima diária mensal durante o período experimental. As produções variaram de 967 a $2.160 \mathrm{~kg} \mathrm{ha}^{-1}$ de MS do capim Tanzânia. Observa-se, na mesma figura, que, em geral, a variação na produção de MS acompanhou a variação da temperatura mínima diária mensal ao longo do ano. Comportamento semelhante foi relatado por Iwamoto et al. (2014) em estudo com o capim Tanzânia no município de Maringá-PR.

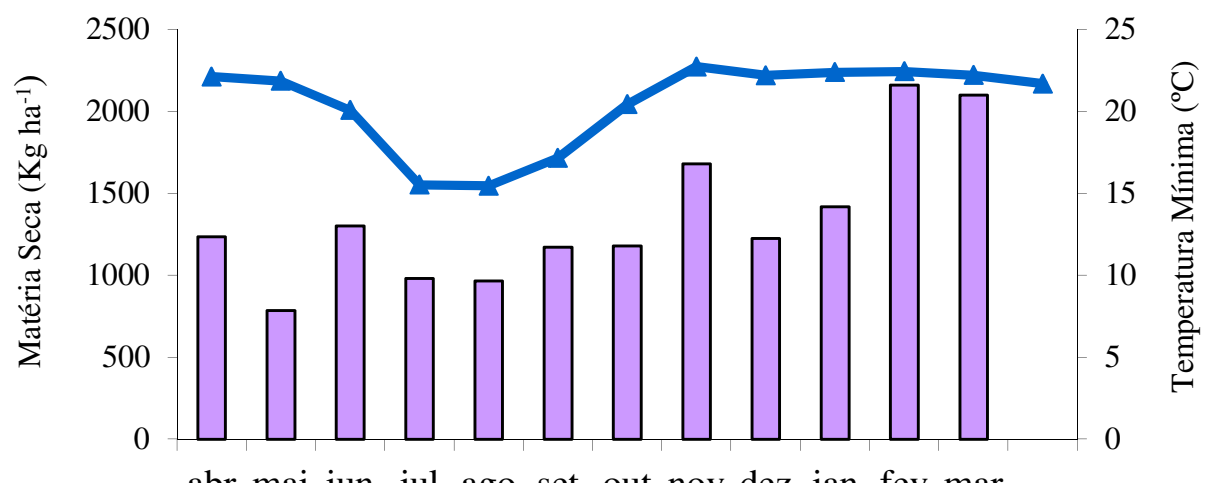

abr mai jun jul ago set out nov dez jan fev mar

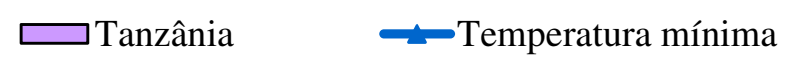

Figura 4. Produtividade de matéria seca do capim Tanzânia e variação da temperatura mínima diária mensal durante o período experimental.

Rolim (1994) mencionou que baixa temperatura noturna nas regiões tropicais e subtropicais seria o principal agente causador da sazonalidade da produção de forragem em capim do gênero Panicum. 


\section{CONCLUSÕES}

1. A produtividade máxima de matéria seca estimada foi de $20.216 \mathrm{~kg} \mathrm{ha}^{-1} \mathrm{ano}^{-1}$ obtida com lâmina de água aplicada igual a $949 \mathrm{~mm}\left(107 \%\right.$ da $\left.\mathrm{ET}_{\mathrm{c}}\right)$ e dose de adubo de $630 \mathrm{~kg} \mathrm{ha}^{1}$ ano $^{-1}$ de N: $0,8 \mathrm{~K}_{2} \mathrm{O}$.

2. O capim Tanzânia apresentou baixa sazonalidade da produção de matéria seca, potencializada principalmente pela irrigação.

3. As lâminas de água e as doses do adubo combinado de $\mathrm{N}: 0,8 \mathrm{~K}_{2} \mathrm{O}$ aplicadas durante o período seco do ano influenciaram positivamente a produtividade de matéria seca.

\section{REFERÊNCIAS}

ALENCAR, C. A. B.; CÓSER, A. C.; MARTINS, C. E.; OLIVEIRA, R. A.; CECON, P. R.; LEAL, B. G. et al. Doses de nitrogênio e estações do ano afetando a composição bromatológica e digestibilidade de capins cultivados sob pastejo. Revista Ceres, Viçosa, v. 56, n. 5, p. 640-647, set./out., 2009.

ALENCAR, C. A. B.; OLIVEIRA, R. A.; COSER, A. C.; MARTINS, C. E.; FIGUEIREDO, J. L. A.; CUNHA, F. F. et al. Produção de seis capins manejados por pastejo sob efeito de diferentes doses nitrogenadas e estacoes anuais. Revista Brasileira de Saúde e Produção Animal, Salvador, v. 11, n. 1, p. 48-58, jan./mar. 2010.

BERnARDO, S.; SOARES, A. A.; MANTOVANI, E. C. Manual de irrigação. 8. ed. Viçosa, MG: Editora UFV, 2006. 625 p.

DERESZ, F. Manejo de pastagem de capim-elefante para produção de leite e carne. In: SIMPÓSIO SOBRE CAPIM-ELEFANTE, 2., 1994, Juiz de Fora. Anais... Coronel Pacheco: EMBRAPA-CNPGL, 1994. p. 116-137.

DIAS FILHO, M. B. Os desafios da produção animal em pastagens na fronteira agrícola brasileira. Revista Brasileira de Zootecnia, v. 40, p. 243-252, 2011.

HANKS, R. J. et al. Line source sprinkler for continuous variable irrigation crop production studies. Soil Science of America Journal, Madison, v. 40, p. 426-429, 1976. http://dx.doi.org/10.2136/sssaj1976.03615995004000030033x

IWAMOTO, B. S.; CECATO, U.; RIBEIRO, O. L.; MARI, G. C.; PELUSO, E. P.; D'ALMEIDA LINS, T. O. J. Produção e composição morfológica do capim-tanzânia fertilizado com nitrogênio nas estações do ano. Bioscience Journal, Uberlândia, v. 30, n. 2, p. 530-538, Mar./Apr. 2014.

JANK, L.; VALLE, C. B.; RESENDE, R. M. S. Grass and forage improvementin the tropics and sub-tropics. In: McGILLOWAY, D. A. (Ed.). Grassland: a global resource. Wageningen: Academic Publishers, 2005. p. 69-80.

PINHEIRO, V. D.; COELHO, R. D.; LOURENÇO, L. F. Viabilidade econômica da irrigação de pastagem de capim Tanzânia em diferentes regiões do Brasil. In: SIPÓSIO SOBRE MANEJO DA PASTAGEM, 19., 2002, Piracicaba. Anais... Piracicaba: FEALQ, 2002. p. $160-188$.

ROLIM, F. A. Estacionalidade de produção de forrageiras. In: PEIXOTO, A. M.; MOURA, J. C. de; FARIA, V. P. de (Ed.). Pastagens: fundamentos de exploração racional. 2. ed. Piracicaba: FEALQ, 1994. p. 533-565. 
ROMA, C. F. C.; CECATO, U.; SOARES FILHO, C. V.; SANTOS, G. T. dos; RIBEIRO, O. S.; IWAMOTO, B. S. Morphogenetic and tillering dynamics in Tanzania grass fertilized and nonfertilized with nitrogen according to season. Revista Brasileira de Zootecnia, Viçosa, v. 41, n. 3, p. 565-573, mar. 2012. http://dx.doi.org/10.1590/S151635982012000300013

SANCHES, A. C.; GOMES, E. P.; RICKLI, M. E.; FASOLIN, J. P.; SOARES, M. R. C.; GOES, R. H. T. B. de. Produtividade e valor nutritivo do capim Tifton 85 irrigado e sobressemeado com aveia. Revista Brasileira de Engenharia Agrícola e Ambiental, v. 19, n. 2, p. 126-133, 2015.

http://dx.doi.org/10.1590/1807-1929/agriambi.v19n2p126-133

SILVA, J. C. A da; FERNANDES, P. D.; BEZERRA, J. R. C.; ARRIEL, N. H. C.; CARDOSO, G. D. Crescimento e produção de genótipos de gergelim em função de lâminas de irrigação. Revista Brasileira de Engenharia Agrícola e Ambiental, v. 18, n. 4, p. 408-416, 2014.

SOARES FILHO, C. V.; RODRIGUES, L. R. A.; PERRI, S. H. V. Produção e valor nutritivo de dez gramíneas forrageiras na região Noroeste do Estado de São Paulo. Acta Scientiarum, Maringá, v. 24, n. 5, p. 1377-1384, 2002.

http://dx.doi.org/10.4025/actasciagron.v24i0.2385 